\title{
Analysis of Coupling Effects between Human Head and Cellular Phone Antennas
}

\author{
Lalit Kumar Jha \\ Research Scholar \\ P. G. Deptt. Of \\ Physics, L. N. M. U \\ Darbhanga, Bihar
}

\author{
S.N. Singh, PhD \\ Deptt. of Physics, \\ C. M. Sc. College, \\ Darbhanga, Bihar
}

\author{
Pramod Jha, PhD \\ Deptt.of Physics, \\ C. M. Sc. College, \\ Darbhanga, Bihar
}

\author{
Neeraj Kumar \\ Cognizant \\ Technology \\ Solutions, Chennai, \\ India
}

\begin{abstract}
This paper presents the synthesis and analysis of a helical antenna for cellular phone. Its coupling effect on human brain has also been investigated in detail. Antenna characteristics parameters such as reflection coefficient, directivity, gain, axial ratio has been observed in presence of SAM human brain phantom. First of all, antenna dimensions has been calculated using MATLAB Program. Further, CST Studio Suite has been used to model and simulate the mobile device in presence of a SAM human head phantom. The signal Absorption Ratio value for the modeled system, and its comparison with the limiting value given by different regulatory authorities present across the globe has been done. On simulating the model, reflection coefficient of the antenna is found to be -37.42 at the operating frequency of $900 \mathrm{MHz}$ Directivity of the circularly polarized antenna is $3.69 \mathrm{dBi}$ and SAR value is $0.889 \mathrm{~W} / \mathrm{kg}$ and $0.597 \mathrm{~W} / \mathrm{kg}$ averaged for $1 \mathrm{~g}$ and $10 \mathrm{~g}$ of tissue respectively.
\end{abstract}

\section{Keywords}

Helical Antenna, Coupling Effect, Human Brain, Signal Absorption Ratio, Reflection Coefficient, Directivity, Circular Polarization

\section{INTRODUCTION}

Modern era has seen tremendous increase in usage of mobile phones and mobile devices throughout the world, which has ultimately boosted the researchers to investigate the effect of mobile phone radiations on human health. These mobile devices use electromagnetic radiations in microwave range which effects the human body. So, study of its impact on human body is significantly justified.

In 2011, Mobile phone radiation has been classified as Group 2B which means these devices are possibly carcinogenic, which means there "could be some risk" of carcinogenicity, from mobile radiations. These findings has led the researchers to conduct the study. In 2014, some national radiation advisory authorities ${ }^{[4-5]}$ have recommended measures to minimize exposure to their citizens as a precautionary approach.

In this research paper, a normal mode helix antenna has been designed for a mobile device and has been simulated in presence of the EN 50361 (SAM, "Specific Anthropomorphic Mannequin") SAM human head phantom to find the coupling effects between human head and mobile device.

\section{THEORY}

\subsection{Helical Antenna}

Radiating element consisting of a conducting wire wound in the form of a helix, is termed as helix antenna. In most cases, helical antennas are mounted over a ground plane. The feed line is connected between the bottom of the helix and the ground plane. Helical antennas can operate in one of the two principal modes known as normal mode and axial mode. In this research work axial mode has been investigated, theory related to calculations of antenna dimensions and performance parameter has been presented briefly.

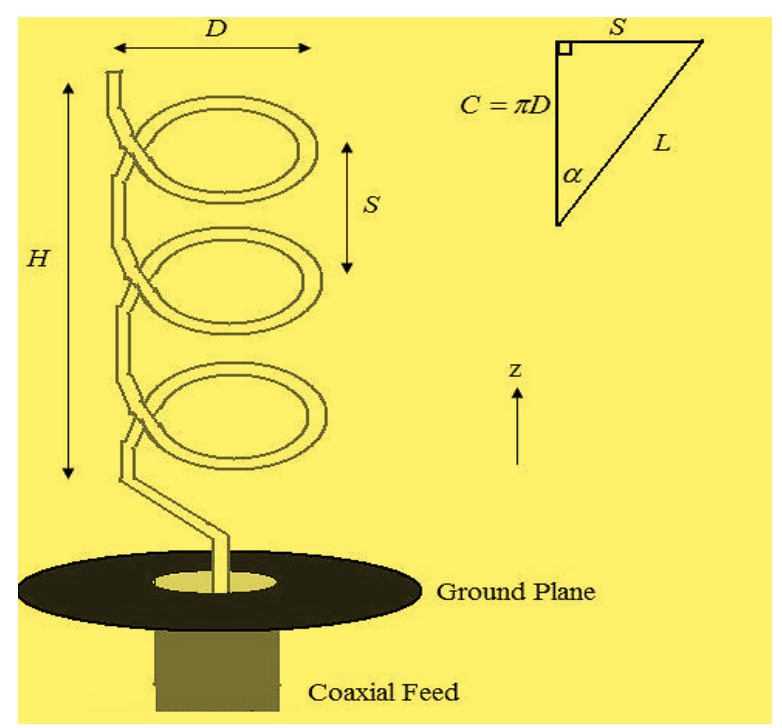

Fig 1: Helical Antenna and its dimensional parameters

Description of dimensional parameters of the helix antenna (shown in figure 1):

- $\quad D$ - Diameter of a turn on the helix antenna.

- $\quad C$ - Circumference of a turn on the helix antenna $\left(C=\mathrm{pi}^{*} D\right)$.

- $\quad S$ - Vertical separation between turns for helical antenna.

- $\quad \alpha$, pitch angle, which controls how far the helix antenna grows in the z-direction per turn, and is given by

$$
\alpha=\tan ^{-1} \frac{s}{c}
$$


- $\quad N$ - Number of turns on the helix antenna.

- $\quad H$ - Total height of helix antenna, $H=N S$.

The helix antenna functions well for pitch angles between 12 and 14 degrees. Typically, the pitch angle is taken as 13 degrees.

In the axial mode or end-fire helix, the dimensions of the helix are comparable to a wavelength $\lambda$ of the radio waves used, which depends on the frequency. The antenna functions as a directional antenna radiating a beam off the ends of the helix, along the antenna's axis. It radiates circularly polarized radio waves.

In axial-mode operation, the spacing between the coils should be approximately one-quarter of the wavelength $(\lambda / 4)$, and the diameter of the coils should be approximately the wavelength divided by pi $(\lambda / \pi)$. The length of the coil determines how directional the antenna will be along with its gain; longer antennas will be more sensitive in the direction in which they point.

Terminal impedance in axial mode ranges between 100 and $200 \mathrm{ohms}$. The resistive part is approximated by:

$$
R \cong 140\left(\frac{c}{\lambda}\right)
$$

where $\mathrm{R}$ is resistance in ohms, $\mathrm{C}$ is the circumference of the helix, and $\lambda$ is the wavelength.

The maximum directive gain has been approximated as:

$$
D_{0} \cong 15 N\left(\frac{C^{2} S}{\lambda^{2}}\right)
$$

Where, $\mathrm{N}$ is the number of turns and $\mathrm{S}$ is the spacing between turns.

The Half-Power Beamwidth is:

$$
H P B W \cong \frac{52 \lambda^{3} / 2}{C \sqrt{N S}}
$$

The Beamwidth between nulls is:

$$
F P B W \cong \frac{115 \lambda^{3 / 2}}{C \sqrt{N S}}
$$

The normalized radiation pattern for the E-field components are given by:

$E_{\theta} \propto E_{\phi} \propto \sin \frac{\pi}{2 N} \cos \theta \frac{\sin \frac{N \Omega}{2}}{\sin (\Omega / 2)}$

$\Omega=\mathrm{kS}(\cos \theta-1)-\pi(2+1 / \mathrm{N})$

For circular polarization, the orthogonal components of the Efield must be 90 degrees out of phase. This occurs in directions near the axis (z-axis in Figure 1) of the helix. The axial ratio for helix antennas decreases as the number of loops $N$ is added, and can be approximated by:

$$
A R=\frac{2 N+1}{2 N}
$$

The gain of the helix antenna can be approximated by:

$$
G=\frac{6.2 N S C^{2}}{\lambda^{2}}=\frac{6.2 C^{2} N S f^{2}}{C^{3}}
$$

where, $c$ is the speed of light. It has been found that in the case of helix antenna, gain increases with increase in operational frequency

\subsection{SAR Signal Absorption Ratio}

A measure for electromagnetic energy absorbed by biological tissue mass (human body) when exposed to radiating device such as mobile phone is termed as "SAR". The maximum power output from a these devices is regulated by the mobile phone standard and by the regulatory agencies in each country. Limiting value of SAR for US and Canada is set to $1.6 \mathrm{~W} / \mathrm{kg}$ averaged over $1 \mathrm{~g}$ of tissue and for EU, Japan, Brazil, value is set to $2.0 \mathrm{~W} / \mathrm{kg}$ averaged over $10 \mathrm{~g}$ of tissue. It is represented is terms of $\mathrm{W} / \mathrm{kg}$. SAR is calculated by using Equation 8:

$$
S A R=\frac{P}{\rho}=\frac{\sigma E^{2}}{2 \rho}=\frac{J^{2}}{2 \rho \sigma}
$$

where, $P$ : Power loss density; $E$ : Electric field strength; $J$ : Current density; $\sigma$ : Conductivity; $\rho$ : density

SAR is calculated as:

- Point SAR: Local SAR without mass or volume averaging

- Total SAR: Total power loss in the whole lossy structure divided by its total mass

Mass Averaged SAR (typically $1 \mathrm{~g}$ or $10 \mathrm{~g}$ ): For each point a cube with a defined mass, SAR is calculated.

\section{CALCULATIONS}

Theoretical calculation for the Helix Antenna operating in Axial Mode as end-fire array has been performed on MATLAB software, where the mathematical equations discussed in Section II have been implemented in MATLAB code to get the desired dimensions of radiating element of the proposed helical antenna design. Input Parameters for Antenna Design in MATLAB has been provided in Table 1 and Table 2 shows the input and output parameters for Antenna Design obtained in MATLAB respectively.

Table 1 Input Parameters for Helix Antenna

\begin{tabular}{|c|c|c|}
\hline S.NO & SPECIFICATION & VALUE \\
\hline 1. & Resonant Frequency (in MHz) & 900 \\
\hline 2. & Number of Turns (N) & 8 \\
\hline 3. & Circumference of loops C (in lambda) & 1 \\
\hline 4. & Spacing between turns S (in lambda) & 0.25 \\
\hline
\end{tabular}

Table 2Output Parameters for Helix Antenna

\begin{tabular}{|c|c|c|}
\hline S.NO & SPECIFICATION & VALUE \\
\hline 1. & Pitch Angle alpha (in degree) & 14.0362 \\
\hline 2. & Input Impedance R (in Ohms) & 140 \\
\hline 3. & Axial Ratio AR (dimensionless) & 1.0625 \\
\hline 4. & Relative phase velocity ratio p & 0.8246 \\
\hline 5. & HBPW (in degrees) & 36.7696 \\
\hline 6. & FNBW(in degrees) & 81.3173 \\
\hline 7. & Directivity (in dB) & 14.7712 \\
\hline
\end{tabular}




\section{SIMULATIONS}

\subsection{Reflection Coefficient}

The power reflected from the antenna is given by the parameter, $\mathrm{S}$ which is also known as the reflection coefficient or the return loss. Figure 2 presents the Return loss curve of the simulated mobile handset antenna. It implies that the helical antenna radiates best at the resonating frequency of $900 \mathrm{MHz}$, return loss obtained is about $-37.42 \mathrm{~dB}$.

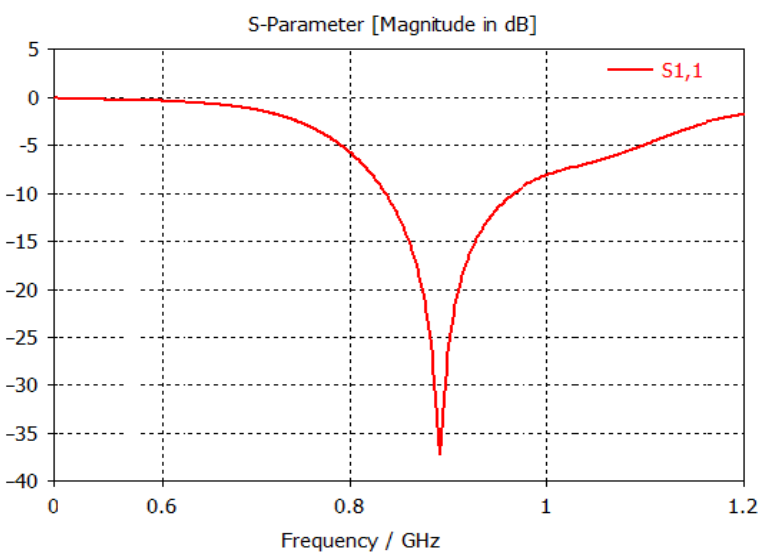

Fig 2: Reflection Coefficient of Radiating System in Presence of SAM Phantom head

\subsection{Axial Ratio}

For pure circular polarization the axial ratio is $0 \mathrm{~dB}$ and for linear polarization the axial ratio is $\infty$. From the $3 \mathrm{D}$ result shown in Figure 3, observation is made about the polarization of Helix Antenna. It is found that the axial ratio changes from $0 \mathrm{~dB}$ to $40 \mathrm{~dB}$, shown with the help of color coding. So, it is deduced that antenna polarization changes from circular to somewhat linear.

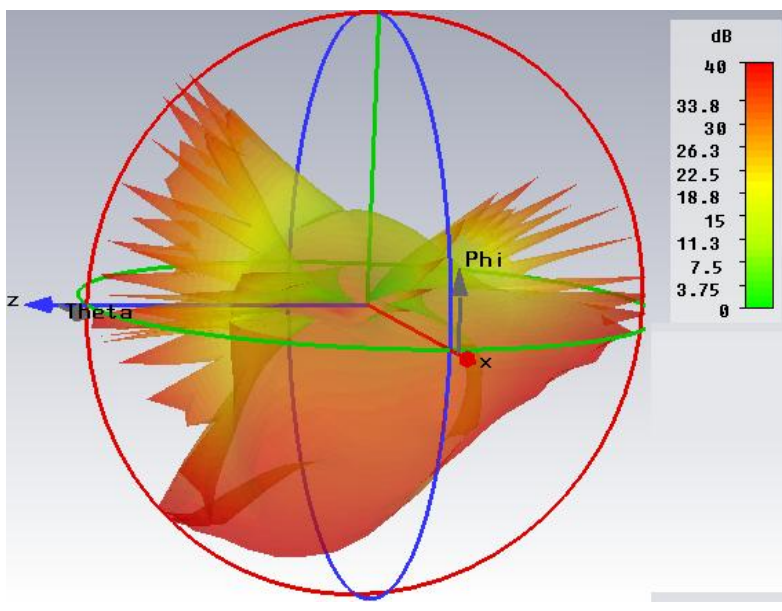

Fig 3: Axial Ratio, AR of Radiating System in Presence of SAM Phantom head

\subsection{Gain}

Power transmitted in the direction of the peak radiation by the synthesized antenna to that of an isotropic antenna source is termed as gain of the synthesized antenna. Antenna gain considers the actual losses occurred in the antenna system. Figure 4 presents the normalized gain of helical antenna as the radiation pattern. Gain of antenna is found to be $3.688 \mathrm{dBi}$ at resonating frequency.

\subsection{Signal Absorption Ratio}

Figure 5 (a) and (b) presents the SAR of the system averaged over $1 \mathrm{~g}$ of tissue and averaged over $10 \mathrm{~g}$ of tissue, respectively. It is found that for $1 \mathrm{~g}$ of tissue, SAR is 0.889 $\mathrm{W} / \mathrm{kg}$ and for $10 \mathrm{~g}$ of tissue, SAR is $0.597 \mathrm{~W} / \mathrm{kg}$. These values are in the acceptable range.

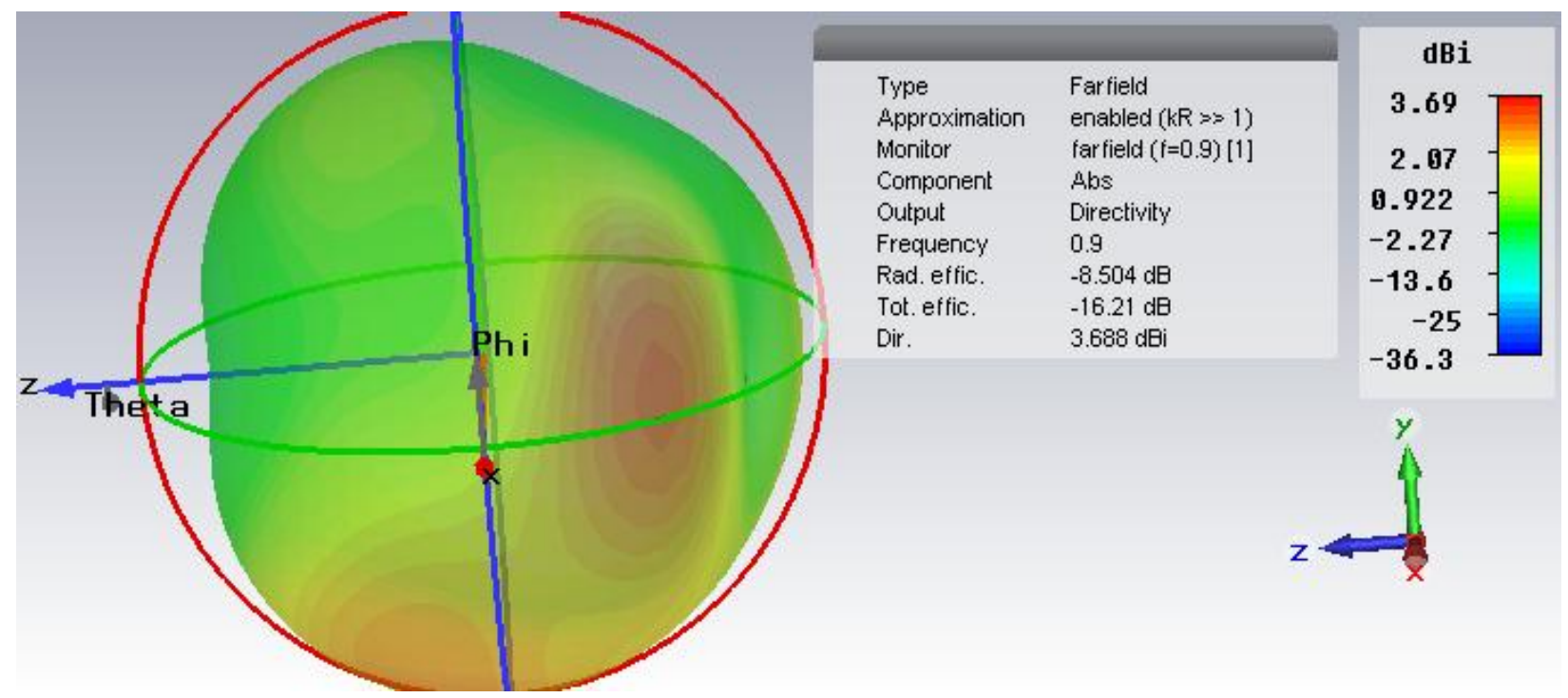

Fig 4: Gain of Radiating System in Presence of SAM Phantom head 

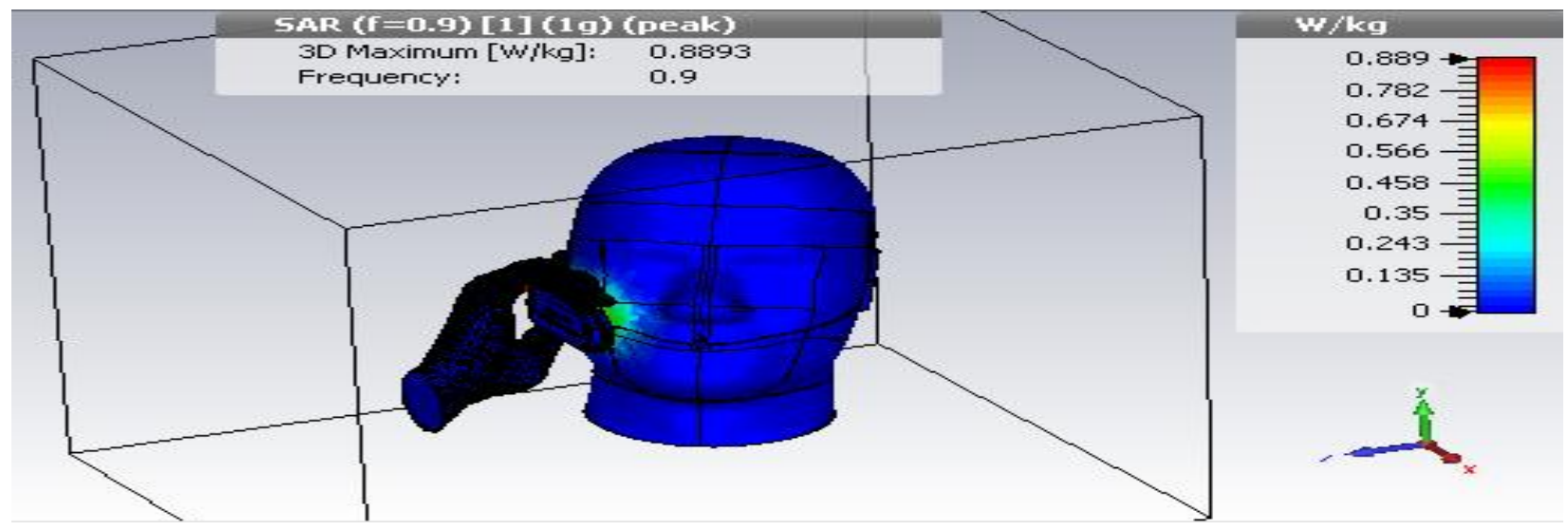

Fig 5 (a): SAR averaged over $1 \mathrm{~g}$ of tissue

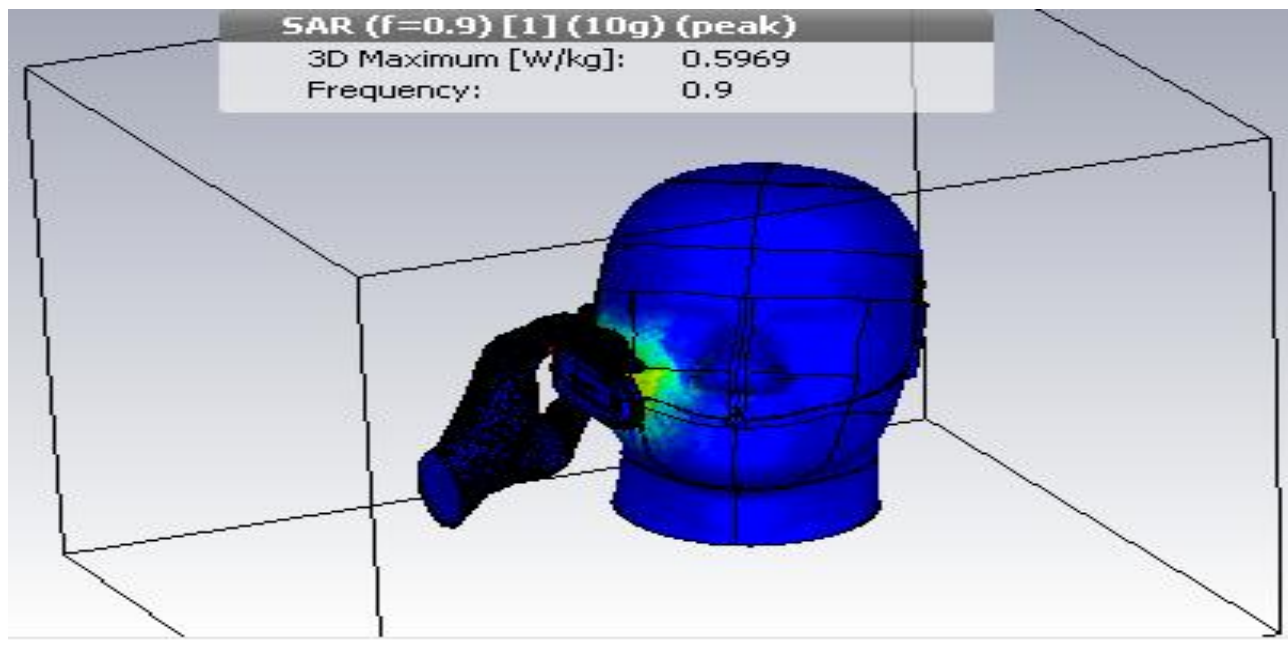

0.597

0.525

0.452

0.38

0.307

0.235

0.163

0.0904

10

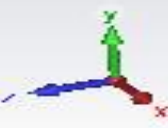

Fig 5 (b): SAR Averaged over $10 \mathrm{~g}$ of Tissue

\section{CONCLUSION}

This research paper presents the helical antenna system as a cellular antenna and finds its coupling effect on human brain. Design of radiating system has been simulated to achieve the SAR value within the prescribed limit. The antenna characteristic parameters has been maintained for the optimum value. CST Studio Suite has been used to simulate the mobile device in presence of a SAM human head phantom, thus finding the SAR value averaged over $1 \mathrm{~g}$ and $10 \mathrm{~g}$ of tissue and it is found that the designed system presents SAR value much below the limit value given across the globe. Reflection coefficient of the antenna is found to be -37.42 at the operating frequency of $900 \mathrm{MHz}$ and directivity of the circularly polarized antenna is $3.69 \mathrm{dBi}$.

\section{ACKNOWLEDGMENTS}

Our thanks to the Department of Physics, C. M. Sc. College, Darbhanga for providing the essential Lab facilities and arranging the essential Journals and research papers referred to accomplish this research work.

\section{REFERENCES}

[1] J. T. Rowley, R. B. Waterhouse, and K. H. Joyner, "Modeling of normal-mode helical antennas at $900 \mathrm{GHz}$ and $1.8 \mathrm{GHz}$ for mobile communications handsets using FDTD technique," IEEE Trans. Antennas Propagation, vol. 50, pp. 812-819, June 2002.

[2] P. Bernardi, M. Cavagnaro, S. Pisa, and E. Piuzzi, "Power absorption and temperature elevations induced in the human head by a dual-band monopole-helix antenna phone," IEEE Trans. Microwave Theory Tech., vol. 49, pp. 2539-2546, Dec., 2001.

[3] M. A. Mangoud, R. A. Abd-Alhameed, and P. S. Excell, "Simulations of human interactions with mobile telephones using hybrid techniques over coupled domains,: IEEE Trans. Antenna Propagation, vol. 48, pp. 2014-2021, Nov. 2000.

[4] K. S. Nikita e.t el., "A study of uncertainties in modeling antenna performance and power absorption in the head of a cellular phone user," IEEE Trans Microwave Theory. Tech., vol. 49, pp. 2676-2687, Dec. 2000.

[5] K. S. Nikita, G. S. Stamatakos, N. K. Uzunoglu, and A. Karafotias, "Analysis of the interaction between a layered spherical human head model and a finite length dipole," IEEE Trans. Microwave Theory Tech., vol. 48., pp. 2003-2013, Nov., 2000. 